\title{
The Effects of Zinc Oxide on the Thermal and Mechanical Properties of Direct Synthesis Hydroxyapatite
}

\author{
Ola Saleh Mahdi* and Israa K Sabree
}

Department of Ceramic Engineering and Building Materials, University of Babylon, Iraq

\begin{abstract}
Effects Zinc oxide $(\mathrm{ZnO})$ of on the mechanical (bending strength and hardness) and thermal stability of hydroxyapatite (HA) that directly synthesized by mechanical milling in a planetary ball mill, using orthophosphoric acid solution $\left(\mathrm{H}_{3} \mathrm{PO}_{4}\right)$ and calcium hydroxide $\mathrm{Ca}(\mathrm{OH})_{2}$ was evaluated. High purity zinc oxide was added in ratios of 10,30 and 50 percent by weight. $\mathrm{HA} / \mathrm{ZnO}$ exhibited increasing in microhardness, and bending strength with increasing amount of $\mathrm{ZnO}$ addition. $X$-ray diffraction after sintering at $1100^{\circ} \mathrm{C}$ for synthesis of hydroxyapatite showed unstable compound, decomposed to $\beta$-TCP, while X-ray for the hydroxyapatite $\mathrm{ZnO}$ contained thermally stable $\mathrm{HA}$ phase and different amounts of $\mathrm{ZnO}$, depending on the amount of $\mathrm{ZnO}$ added.
\end{abstract}

Keywords: Zinc oxide; Hydroxyapatite (HA); Mechanical activation; Milling

\section{Introduction}

Mechanosynthesis method is an alternate routine to prepare hydroxyapatite through that reaction stimulate by mechanical grinding [1]. The reactants in a mill are crushed between wall and ball (horizontal or planetary ball mill. Mixtures imbibe quantity of frictions or collisions energy in case through that deliver the energy required for reaction [2]. Mechanosynthesis can be achieved below wet or dry situations. Wet mechanosynthesis contains crushing in an aqueous interruption of the initial resources (wet abrasion or mechanochemicalhydrothermal route) with a fluid-to-powder proportion reaching normally from 60 to 95 wt.\% ) [3]. In dry mechanosynthesis, powders mixture without any solvent are straight crushed. In papers record and charters regarding mechanosynthesis grinding of calcium phosphates, was achieved in wet environments [4]. The reactions want high temperatures in mechanochemical treating, will happen in a ball mill at lower temperatures without some requisite for outside heating [5]. Technical inquiry through scientists materials must been always focused to ameliorative the performance and properties of materials [6]. Important developments in chemical, physical and mechanical properties have been realized done chemistry alterations and thermal, thermo mechanical and mechanical treating procedures [7]. Hydroxyapatite $\left(\mathrm{Ca}_{10}\left(\mathrm{PO}_{4}\right)_{6}(\mathrm{OH})_{2}\right)$, categorized as a biomaterial, is a fabricated material accustomed substitute parts of a alive organization or to purpose in near interaction with alive tissues [8]. This material is current in considerable quantities in the mineralized tissue of vertebrates, i.e., $60-70 \%$ of the inorganic part of the human bone [9]. The mechanical properties of hydroxyapatite are not perfect sufficient to be applied as an graft in load-bearing locations, similar artificial teeth or bones [10]. One path to disband this trouble is to join it with a hard phase, creating a compound and improve its mechanical confines by strengthening it with appropriate material [10]. In this method, a material is achieved with heightened belongings, without harm to its biocompatibility [11]. Zinc oxide presentation several aids for bone development and an antimicrobial activity for grafts, stimulates growth of bone prevents bone recommencement presentation antimicrobial opposition [12]. The obtainability of zinc concludes the performance and this can be deliberate by the microstructure (crystal size, form, and crystallinity, of zinc [13]. Innermost trainings mingle zinc from an aquatic sol in apatite crystallization and determination several difficulties. Zinc meaningfully reductions the mineral evolution amount through adsorbing to the external [14]. Synthesis of hydroxyapatite using a mechanochemical process was investigated in this research work. Initially, the objective was to synthesize HA directly without the need for a two-stage process where mechanical activation for 6 hours was followed by a heat treatment process at $1100^{\circ} \mathrm{C}$ [15]. The milling parameters were systematically investigated, and these included the milling duration, the types of milling media and ball toward powder ratio. The use of milling media, i.e., the balls and the jars, was restricted to the same material as compared to dissimilar materials which had been reported in the literature [16].

The ultimate objective of the present work was to synthesize a single phase hydroxyapatite directly by mechanical milling using orthophosphoric acid solution $\left(\mathrm{H}_{3} \mathrm{PO}_{4}\right)$, and calcium hydroxide, $\mathrm{Ca}$ $(\mathrm{OH})_{2}$, equally the originators without any need for heat treatment, and communicate the mechanical, structural, and bioactive belongings of hydroxyapatite- zinc oxide biomaterials by different installation of zinc oxide.

\section{Materials and Procedures}

\section{Raw materials}

In this work commercially precursors utilized orthophosphoric acid solution $\left(\mathrm{H}_{3} \mathrm{PO}_{4}\right)$ and calcium hydroxide, $\left(\mathrm{Ca}(\mathrm{OH})_{2}\right.$, and zinc oxide, Fluka, 96\%).

\section{Hydroxyapatite preparation}

In effective production hasten to produce single-phase HA only, first $100 \mathrm{~mL}$ of ethanol was located into a amplitude Pyrex of $100 \mathrm{~mL}$. additional powder $\mathrm{Ca}(\mathrm{OH})_{2} 2.96 \mathrm{~g}$ of $(50.0296 \mathrm{~mol} \mathrm{Ca})$ into ethanol and made dense suspension was stirred magnetically for $5 \mathrm{~min}$ at room

*Corresponding author: Ola Saleh Mahdi, Department of Ceramic Engineering and Building Materials, University of Babylon, Iraq, Tel: 47801006256; E-mail: engoulasaleh.alsaffar@yahoo.com

Received November 18, 2017; Accepted December 25, 2017; Published January 02, 2018

Citation: Mahdi OS, Sabree IK (2018) The Effects of Zinc Oxide on the Thermal and Mechanical Properties of Direct Synthesis Hydroxyapatite. Ind Eng Manage S3: 001. doi: 10.4172/2169-0316.S3-001

Copyright: ( 2018 Mahdi OS, et al. This is an open-access article distributed under the terms of the Creative Commons Attribution License, which permits unrestricted use, distribution, and reproduction in any medium, provided the original author and source are credited. 
Citation: Mahdi OS, Sabree IK (2018) The Effects of Zinc Oxide on the Thermal and Mechanical Properties of Direct Synthesis Hydroxyapatite. Ind Eng Manage S3: 001. doi: 10.4172/2169-0316.S3-001

Page 2 of 6

temperature. Supplementary $\mathrm{H}_{3} \mathrm{PO}_{4}, 4 \mathrm{~mL}$ of $(50.0592 \mathrm{~mol} \mathrm{P})$ into the suspension of calcium hydroxide. Wet mixed in a planetary ball mill (SFM-1, QM-3SP2) with runs at $400 \mathrm{rpm}$. The wet mixture was oven dried at $100^{\circ} \mathrm{C}$ for 24 hours to be sure that all moisture was removed. Orderly to evade heat extreme, 30 minutes milling intervals with 2 minutes pause milling was carried out. The milling media to start off with was alumina (ball and jar) and the ball-to-powder ratio (BPR) was fixed at 10:1, a milling duration of 6 hours. Figure 1 shows the typical processes used to produce the hydroxyapatite powder.

\section{Hydroxyapatite (HA) zinc oxide ( $\mathrm{ZnO}$ ) preparation}

The fine powders of the zinc oxide $(\mathrm{ZnO})$ was mingled with the powder of hydroxyapatite (HA) was obtained from the method described earlier in a mode that the definitive combinations consist of 10,30 , and $50 \mathrm{wt} \%$ of the $(\mathrm{ZnO})$. The combinations were fully standardized till 4 hours through ball milling. Prepared pellets $(13 \mathrm{~mm}$ diameter, $26 \mathrm{~mm}$ height) were by uniaxial cold pressing in hardened steel dies, using uniaxial pressure device (CT340-CT440) at pressure of $150 \mathrm{MPa}$. The pellets were sintered at $1200^{\circ} \mathrm{C}$ for 2 hours with an average heating rate of $7^{\circ} \mathrm{C} / \mathrm{min}$.

\section{Characterization}

\section{$\mathrm{X}$-ray diffraction $(\mathrm{XRD})$}

$\mathrm{X}$-ray diffract meter (Shimadzo, 6000) at room temperature using $\mathrm{Cu}$ ka radioactivity $\left(\lambda=1.5405 \mathrm{~A}^{\circ}\right)$, and $40 \mathrm{KV} / 30 \mathrm{~mA}$ was used as the main analytical tool.

\section{Particle size analyzer}

Particle size for prepared (HA) powder was measured using laser particle size analyzer

\section{Mechanical properties}

Bending strength and microhardness for the (HA) and for $(\mathrm{HA}) /(\mathrm{ZnO})$ samples were tested. The computerized universal experimentation machine with a speed test of $0.5 \mathrm{~mm} / \mathrm{min}$ using to determine bending strength test using rectangular bar samples prepared with dimensions of (Length $=50 \mathrm{~mm}$, Width $=10 \mathrm{~mm}$, Height $=5 \mathrm{~mm}$ ), the samples prepared according to the ASTM-D790 in steel die. The test was made according to ASTMC1161 procedure. The subsequent equation consuming to intentional strength of bending.

$(\sigma \mathrm{b})=3 \mathrm{pfL} / 2 \mathrm{wt} 2$
Where, is the bending strength (Mpa), pf, fracture load $(\mathrm{N}), \mathrm{w}$, the sample width $(\mathrm{mm}), \mathrm{t}$, the sample thickness $(\mathrm{mm})$ [17]. Microhardness for all samples were tested using Digital microvickers hardness tester (TH-717) at $9.8 \mathrm{~N}$ with a dwelling time of 15 second. Disc samples prepared with samples prepared in steel die. The test was made according to ASTM standard C1327-90. Vickers hardness was deliberated by the subsequent equation.

$\mathrm{Hv}=1.854(\mathrm{p} / \mathrm{d} 2)$

Wherever, $\mathrm{H}_{\mathrm{v}}$, Vickers hardness (Mpa), p, pregnancy $(\mathrm{N}), \mathrm{D}$, diagonal length of the indentation impression $(\mu \mathrm{m})[18]$.

\section{Results and Discussion}

\section{$\mathrm{X}$-ray diffraction (XRD)}

Figure 2 displays the result for complete reaction for the batch, a single-phase HA can be successfully obtained. The powder of hydroxyapatite was scanned in diffraction angle $(2 \Theta)$ from $5^{\circ}$ to $50^{\circ}$. This result is matched with (JCPDS) card No. (09-0432). Figure 3 shows $\mathrm{XRD}$ patterns of sintered $\mathrm{HA}$ at $1000^{\circ} \mathrm{C}$. Hydroxyapatite is thermally unstable compound, decomposed at temperature $1000^{\circ} \mathrm{C}$ to $\beta$-TCP. The resulting of decomposition is started at $800^{\circ} \mathrm{C}$, to give correct calcium orthophosphate of the composition stoichiometric $\mathrm{Ca}_{3}(\mathrm{PO} 4)_{2}$ phase when matching its peaks with (JCPDS) card No. (09-0169).

Figure $4 \mathrm{~A}$ and $4 \mathrm{~B}$ illustration XRD configurations for $\mathrm{HA}-\mathrm{ZnO}$ models contained 10 and $50 \mathrm{wt} \%$ of the $(\mathrm{ZnO})$ sintered at $1200^{\circ} \mathrm{C}$ for $2 \mathrm{~h}$. The powder of $\mathrm{HA}-\mathrm{ZnO}$ was scanned in diffraction angle $(2 \Theta)$ from $10^{\circ}$ to $60^{\circ}$. Phase stability for the crystallized apatites still shows at higher temperatures sintering without decomposition and different amounts of $\mathrm{ZnO}$ phase when matching its peaks with (JCPDS) card No. (13-0311). This also provides direct evidence that $(\mathrm{ZnO})$ incorporations into apatite, enriched thermal stability of amorphous calcium phosphate up to $1000^{\circ} \mathrm{C}$. leading to higher crystallization temperatures [19].

\section{Particle size analysis}

Figure 5 shows the particle size analysis of HA powder to give an average particle size of $73 \mathrm{~m}$.

\section{Bending strength and Vickers hardness}

Figures 6 and 7 shows the relation between the HA- $\mathrm{ZnO}$ samples with different weight percent of $\mathrm{ZnO}$ and bending strength, and Vickers hardness. The increase in bending strength and hardness is detected as the content of $\mathrm{ZnO}$ increases in the models compare to

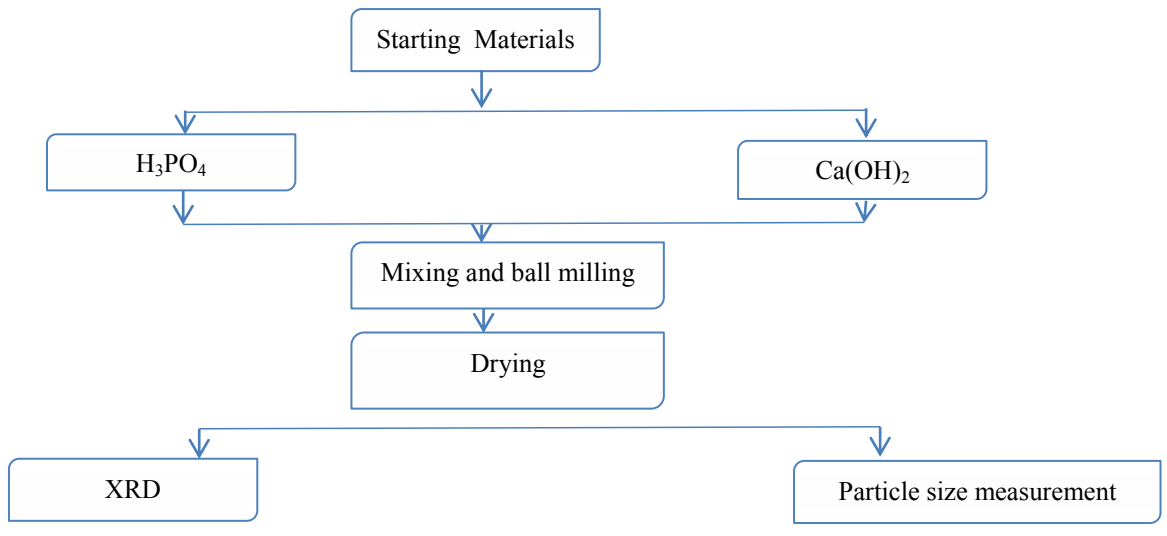

Figure 1: Schematic diagram of preparation hydroxyapatite powder. 


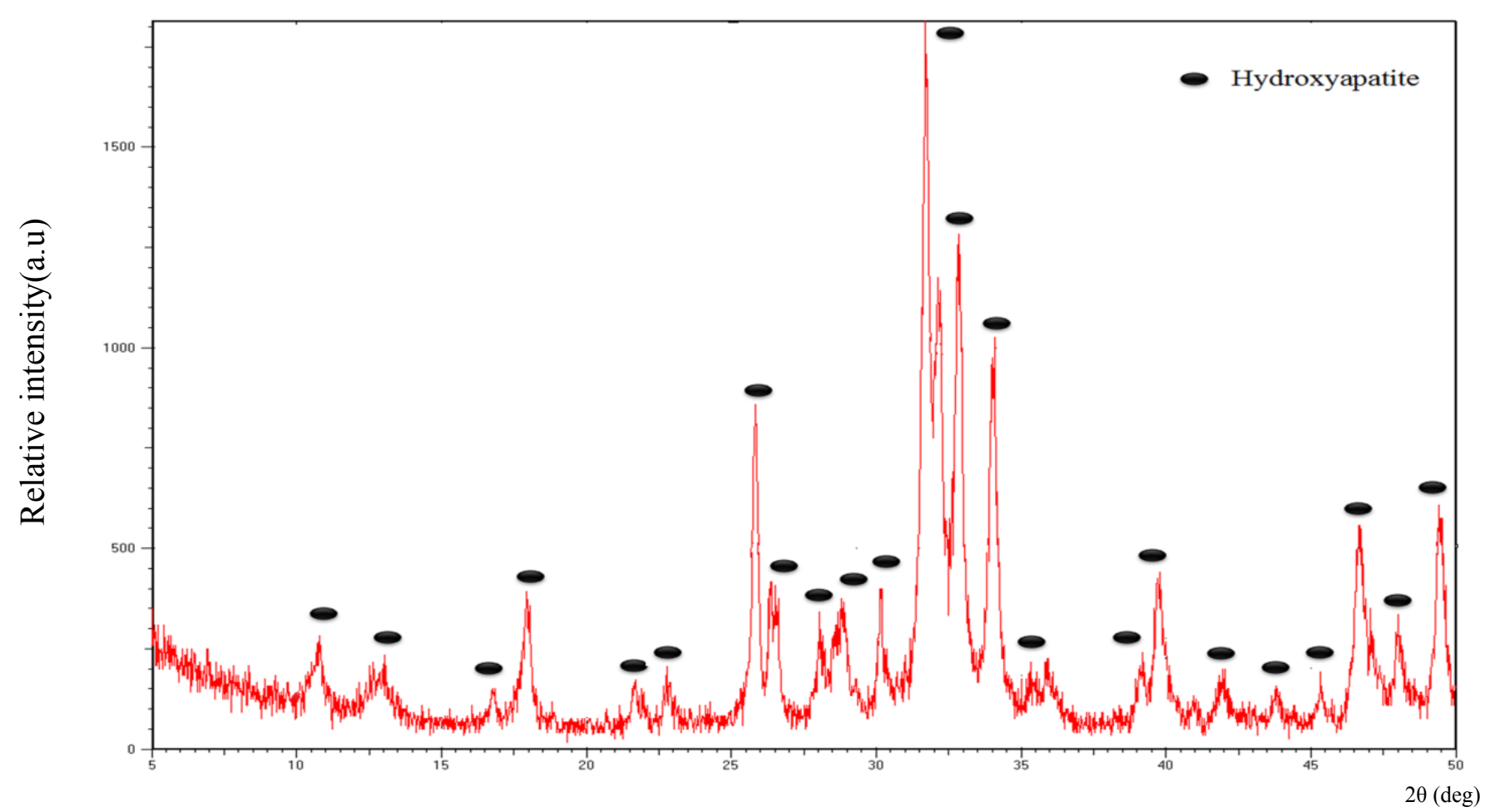

Figure 2: XRD patterns of hydroxyapatite (HA) that directly synthesized by mechanical milling.

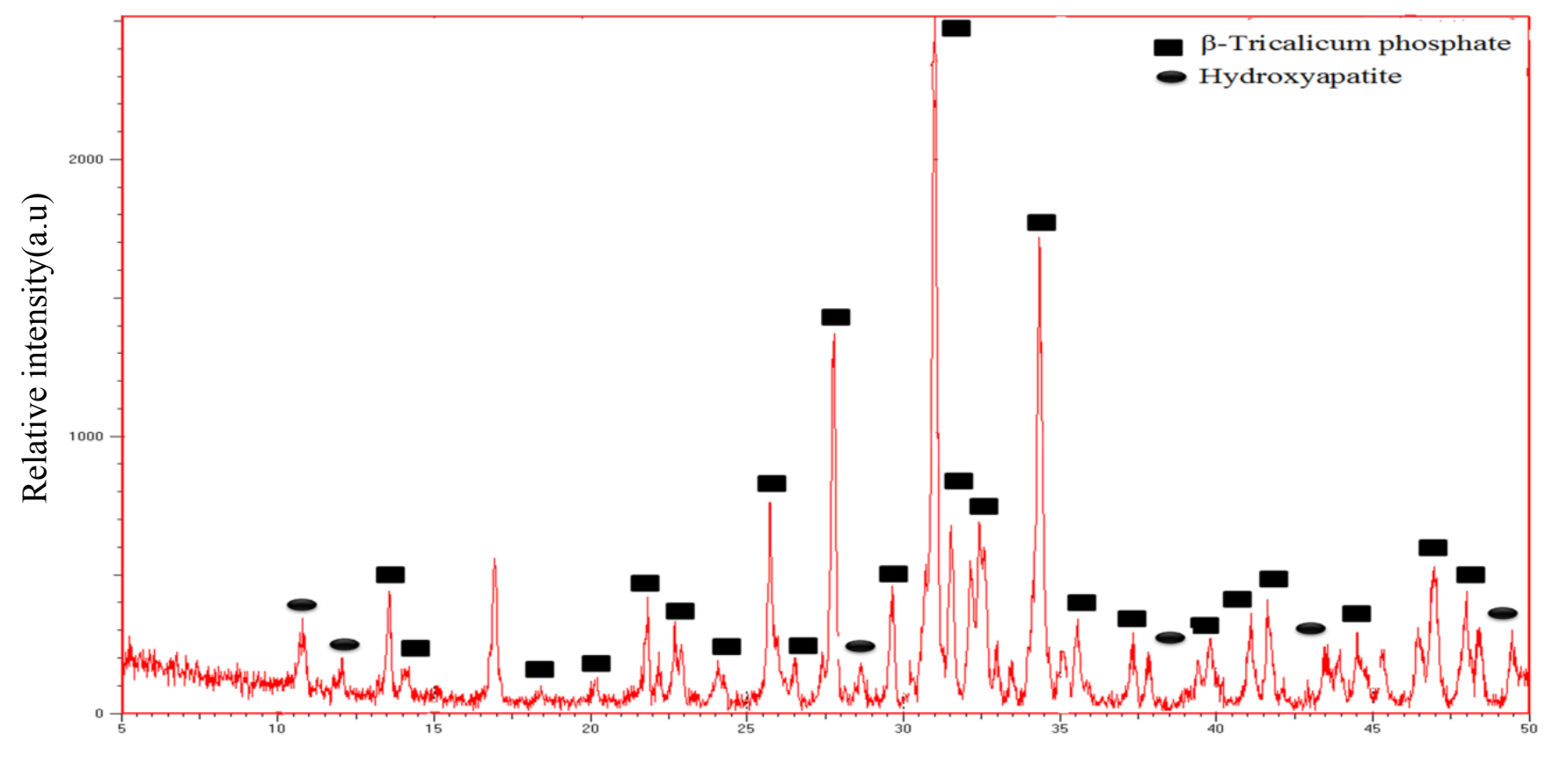

Figure 3: XRD configurations of hydroxyapatite $(\mathrm{HA})$ sintered at $1000^{\circ} \mathrm{C}$

the pure hydroxyapatite. This is a lucid significance of exactly how the addendum of $\mathrm{ZnO}$ to the syntheses improves their heftiness [19]. The results shown in Table 1.

\section{Conclusion}

1. Finer powder hydroxyapatite (HA) directly synthesized by mechanical milling in a planetary ball mill, using orthophosphoric acid solution $\left(\mathrm{H}_{3} \mathrm{PO}_{4}\right)$ and calcium hydroxide $\mathrm{Ca}(\mathrm{OH})_{2}$. The optimization was confirmed principally with $\mathrm{X}$-ray diffraction (XRD) which indicated that only a single phase hydroxyapatite was the final product in this milling reaction. 


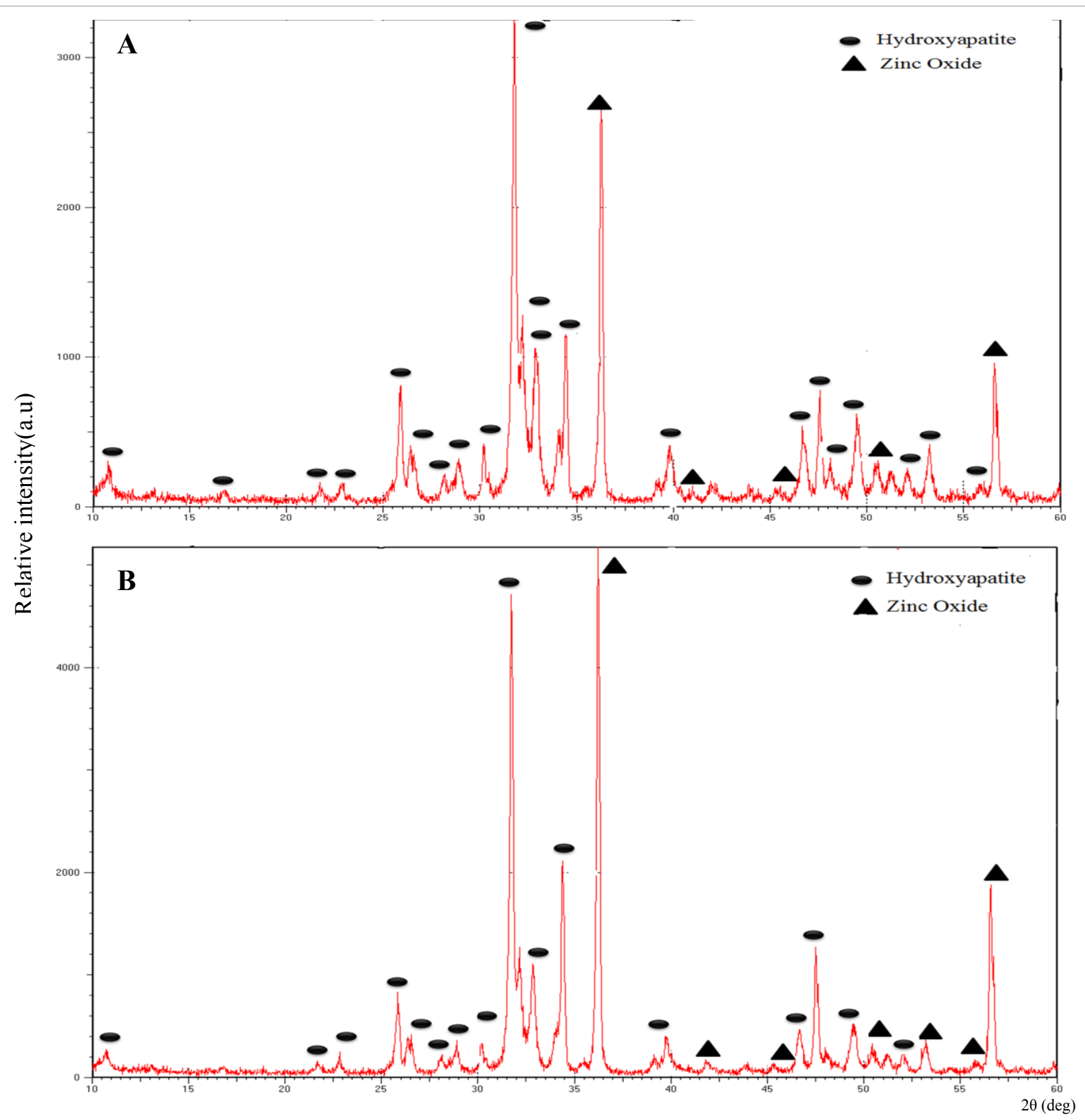

Figure 4: XRD configurations for the ( $\mathrm{HA}-\mathrm{ZnO})$ samples of $\mathrm{A}(30 \%), \mathrm{B}(50 \%)$ of the $(\mathrm{ZnO})$ sintered at $1200^{\circ} \mathrm{C}$.

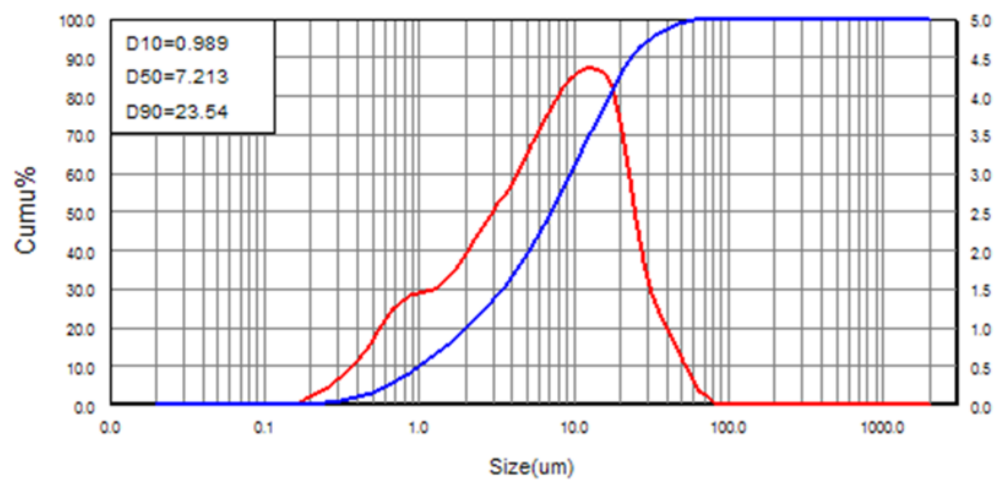

\begin{tabular}{|c|c|}
\hline Diam um & Pereent \\
\hline 0.200 & 0.09 \\
\hline 0.500 & 3.12 \\
\hline 1.000 & 10.18 \\
\hline 2.000 & 19.47 \\
\hline 5.000 & 39.10 \\
\hline 10.000 & 61.12 \\
\hline 20.000 & 85.51 \\
\hline 45.000 & 98.28 \\
\hline 75.000 & 99.96 \\
\hline 100.000 & 100.00 \\
\hline
\end{tabular}

Figure 5: Particle size analysis of HAP powder. 
Citation: Mahdi OS, Sabree IK (2018) The Effects of Zinc Oxide on the Thermal and Mechanical Properties of Direct Synthesis Hydroxyapatite. Ind Eng Manage S3: 001. doi: 10.4172/2169-0316.S3-001

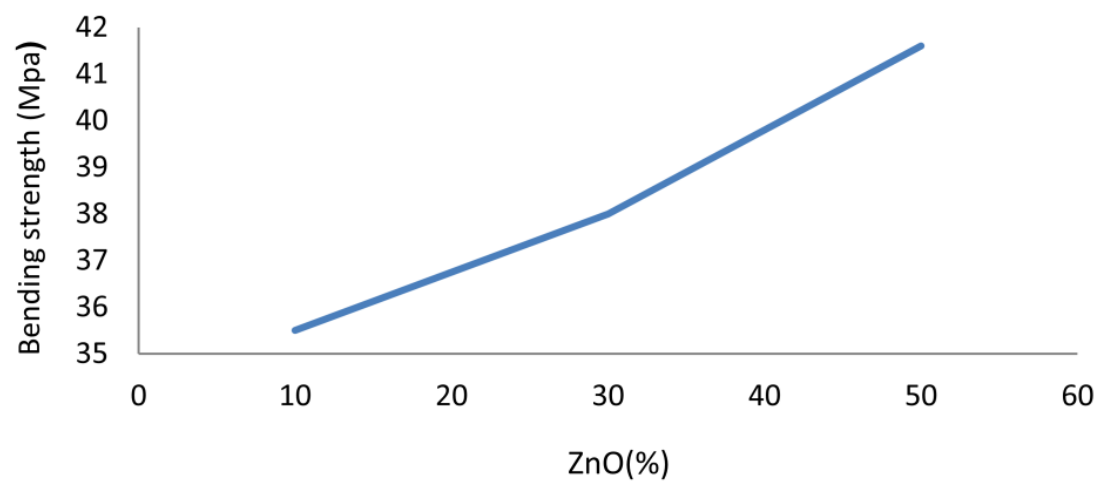

Figure 6: Variation of bending strength of the $\mathrm{HA}-\mathrm{ZnO}$ samples with $\mathrm{ZnO}$ percentage

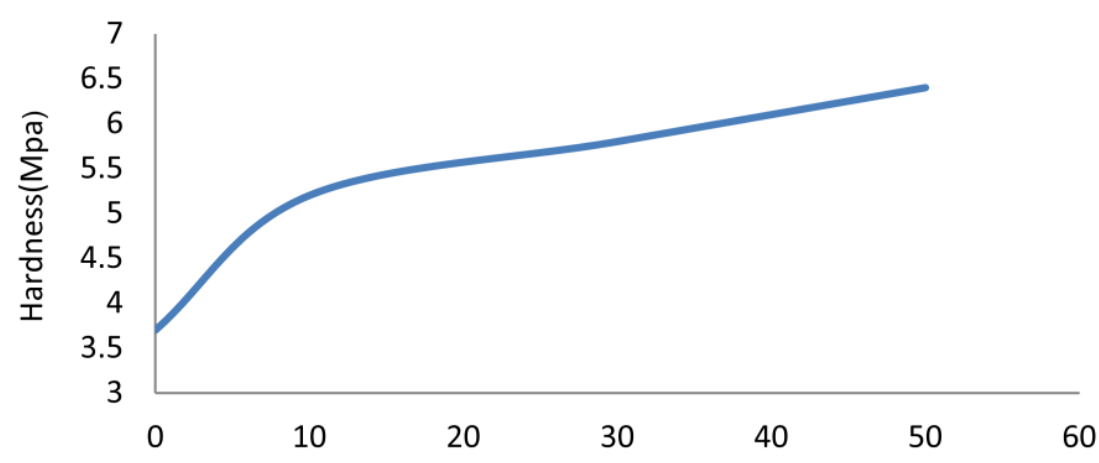

(\%) ZnO

Figure 7: Variation of Vickers hardness of the HA-ZnO samples with $\mathrm{ZnO}$ percentage.

\begin{tabular}{|l|c|c|c|c|}
\hline & HA \% & ZnO \% & $\begin{array}{c}\text { Bending strength } \\
\text { (MPa) }\end{array}$ & $\begin{array}{c}\text { Vickers hardness } \\
\text { (Mpa) }\end{array}$ \\
\hline Sample 1 & 100 & 0 & 32.5 & 3.7 \\
\hline Sample2 & 90 & 10 & 35.5 & 5.2 \\
\hline Sample3 & 70 & 30 & 38.0 & 5.8 \\
\hline Sample4 & 50 & 50 & 41.6 & 6.4 \\
\hline
\end{tabular}

Table 1: Summary of the mechanical properties for the HA-ZnO samples.

2. High purity zinc oxide $(\mathrm{ZnO})$ was added in ratios of 10,30 and 50 percent by weight. It was found that addition of $(\mathrm{ZnO})$ to the hydroxyapatite matrix in the rate of $(10,30,50)$ wt.\% lead to increase the mechanical properties ( hardness and bending strength).

3. HA ceramic prepared from mechanochemical synthesis powders is thermally stable compound, decomposed at sintering temperature $1000^{\circ} \mathrm{C}$ to $\beta$-TCP.

4. After sintering process for $\mathrm{HA}-\mathrm{ZnO}$ samples at $1200^{\circ} \mathrm{C}$ for 2 hours. X-Ray results at higher temperatures still shows phase stability for the crystallized apatites without decomposition and different amounts of $\mathrm{ZnO}$ phase.

5. The $(\mathrm{ZnO})$ incorporations into apatite enhance the thermal stability the $\mathrm{HA}-\mathrm{ZnO}$ samples tested up to $1000^{\circ} \mathrm{C}$ of, unlike apatites produced by mechanical milling.

\section{References}

1. Yeong KCB, Wang J, Ng SC (2001) Mechanochemical synthesis of nanocrystalline hydroxyapatite from $\mathrm{CaO}$ and $\mathrm{CaHPO}_{4}$. Biomaterials 22: 2705-
2. Gonzalez G, Sagarzazu A, Villalba $R(2006)$ Mechanochemical transformation of mixtures of $\mathrm{Ca}(\mathrm{OH})_{2}$ and $\left(\mathrm{NH}_{4}\right)_{2} \mathrm{HPO}_{4}$ or $\mathrm{P}_{2} \mathrm{O}_{5}$. Material Research Bulletin 41: 1902-1916.

3. Elliot JC (1994) Structure and chemistry of the apatites and other calcium orthophosphates. Studies in inorganic chemistry. Amsterdam Elsevier, p: 404.

4. Silva CC, Pinheiro AG, Miranda MAR, Goes JC, Sombra ASB (2003) Structural properties of hydroxyapatite obtained by mechanosynthesis. Solid State Sciences 5: 553-558.

5. Deptula A, Lada W, Olczak T, Borello A, Alvani C, et al. (1992) Preparation of spherical powders of hydroxyapatite by sol-gel process. Journal of Noncrystalline Solids 148: 537-541.

6. Hattori T, Iwadate $\mathrm{Y}$, Kato K (1989) Hydrothermal synthesis of hydroxyapatite from calcium pyrophosphate. Journal Material Science Letter 8: 305-306.

7. Ojima A, Naito K, Ichinose H, Tateishi N (2000) Preparation, solubility, and cytocompatibility of zinc-releasing calcium phosphate ceramics. J Biomed Mater Res 5: 178- 83.

8. Miyaji F, Kono Y, Suyama Y (2005) Formation and structure of zinc substituted calcium hydroxyapatite. Mater Res Bull 40: 209-220.

9. Bigi A, Foresti E, Gandolfi M, Gazzano M (1995) Inhibiting effect of zinc on hydroxylapatite crystallization. J Inorg Biochem 49: 49-58.

10. Gomes S, Nedelec JM, Renaudin G (2012) On the effect of temperature on the insertion of zinc into hydroxyapatite. Acta Biomater 8: 1180-1189.

11. Hu W, Wang J, Zhang S (2012) Fine structure study on low concentration zinc substituted hydroxyapatite nanoparticles. Mat Sci Eng C 24: 4-10

12. Mondal S, Mondal B, Dey A, Mukhopadhyay SS (2012) Studies on Processing and Characterization of Hydroxyapatite Biomaterials from Different Bio Wastes. Journal of Minerals \& Materials Characterization \& Engineering 11: 55-67.

13. Rey C, Combes C, Drouet C (2008) Tricalcium phosphate-based ceramics Wood head Publishing Limited and CRC Press LLC. 
Citation: Mahdi OS, Sabree IK (2018) The Effects of Zinc Oxide on the Thermal and Mechanical Properties of Direct Synthesis Hydroxyapatite. Ind Eng Manage S3: 001. doi: 10.4172/2169-0316.S3-001

Page 6 of 6

14. De Aza PN (2006) Progress in Bioceramic Materials. Nova Science Inc pp: 101-132.

15. Park J (2008) Bioceramics: Properties, characterizations, and Applications

16. George Quinn D, Brian Sparenberg T, Koshy P, Lewis Ives K, Jahanmir S et al. (2009) Flexural Strength of Ceramic and Glass Rods. Journal of Testing and Evaluation 37: 1-3.
17. Roy M (2010) Vickers Hardness Measurements: Practices and Calibration Check. The University Of British Columbia.

18. Uchino T, Toda K (2013) Synthesis of zinc- containing amorphous calcium phosphate. Key Engin Mater. Bioceramics 24 530: 119-122.

19. Kutz M (2002) Handbook of Materials Selection by John Wiley \& Sons, p: 1496. 